\title{
Self-Care a Buzz Word during COVID-19 Pandemic
}

\author{
Harshal Tukaram Pandve ${ }^{1, *}$, and Sarika Prashant Patil ${ }^{2}$ \\ ${ }^{1}$ Professor and Head, Department of Community, Medicine, ESIC Medical College, India \\ ${ }^{2}$ Associate Professor, Department of Community, Medicine, SBH Government Medical College, India
}

*Corresponding author: Harshal Tukaram Pandve, Professor and Head, Department of Community, Medicine, ESIC Medical College, India, E-mail: dr_harshalpandve@yahoo.co.in

Received: 9 Sep, 2020 | Accepted: 25 Sep, 2020 | Published: 30 Sep, 2020

Citation: Pandve HT, Patil SP (2020) Self-Care a Buzz Word during COVID-19 Pandemic. J Epidemiol Public Health Rev 5(3): dx.doi. org/10.16966/2471-8211.199

Copyright: (c) 2020 Pandve HT, et al. This is an open-access article distributed under the terms of the Creative Commons Attribution License, which permits unrestricted use, distribution, and reproduction in any medium, provided the original author and source are credited.

As per World Health Organization (WHO), health is a state of complete physical, mental and social well-being and not merely the absence of disease or infirmity [1]. The novel coronavirus disease (COVID-19) that emerged at the end of 2019 began threatening the health of millions of people. World Health Organization has declared COVID-19 pandemic as public health emergency of national and international concern. This pandemic is affecting health by the physical, mental and social measures of well-being, but also the financial and environmental measures of well-being.

Self-care is any activity that we do deliberately in order to care for what we define as "self". Gallup and the Planet Earth Foundation research the cultural construct of wellbeing in self and find a great range of variables with only relationships and contribution to hold true throughout the globe. In a Western context it's a simple concept in theory and it's something that very often overlooked [2]. One's ability to promote health, prevent disease, maintain health, and cope with illness and disability with or without the support of a professional health-care provider is known as self care. In simple words, self-care is asking yourself what care you can provide alone and what actions might be requested from others in your community. During this COVID-19 pandemic "Self-care" has to be a buzz word. Physical distancing, good respiratory hygiene and hand washing are important examples of selfcare actions you can take every day to protect against COVID-19, and there are many other areas in which self care can make a difference during the coronavirus disease pandemic [3]. The physical, mental, social, financial and environmental healths are not separate houses, but rather ways the western world choices to construct a "self". All aspects of wellbeing and therefore health are interconnected can be maintained by connection and thoughtful application of resources to water, nutrition, rest, movement, laughter and caring for something other than your own needs. Self-care looks very simple and may seem doable all the time, but it is not always embodied. Sometimes simplest of the self-care activities is where we start. Do one thing that honors your value in the world, like a mid-day nap or a break to stretch and study the sky. During this COVID-19 pandemic we need to help each other in our self-care with kindness and curious caring questions for even the act of asking about another is an acknowledgement of the need for the mutuality of self-care.

Looking at global figures of number of patients of COVID-19 it seems that many of us may be wanting for self-care. To conclude, taking care of guidelines to avoid COVID-19 infection, taking care of nutrition and movement and taking care of thoughts and thinking process to avoid catastrophizing or rumination is key to survival during the COVID-19 pandemic.

\section{References}

1. Grad FP (2002) The Preamble of the Constitution of the World Health Organization. Bull World Health Organ 80: 981-984.

2. Michael R (2018) What Self-Care Is-and What It Isn't. Psychcentral, United States.

3. World Health Organization (2020) Self care during COVID-19. WHO, Geneva, Switzerland. 